\title{
A Study on Management countermeasures for Vocational School Underachievers Based on Game Theory Analysis
}

\author{
Guanghua Li \\ Department of Power Generation and New Energy \\ Resource \\ State Grid of China Technology College \\ Jinan, China \\ leegh195@yahoo.cn
}

\author{
Pingying Li \\ School of Economic and Management \\ Shandong Agriculture University \\ Taian, China \\ oldestsky@sdau.edu.cn
}

\author{
Xiaoling Wang \\ Operational Department of State Grid \\ State Grid of China Technology College \\ Jinan, China \\ wx19510@sohu.com
}

\begin{abstract}
Vocational school underachiever problem becomes more and more serious. Part of the reasons including: Expansion of vocational school recruitment leads to the decrease of student quality, and social environment students facing has dramatically changed. The Underachiever's formation is result of interaction between internal and external factors, so underachiever problem must be solved from two aspects, students' own factors and social environment. In this paper the author discusses the mechanism of choice of student behavior, uses basic method of game theory to establish student behavior choice model, then puts forward corresponding management measures from two aspects.
\end{abstract}

Keywords-vocational school underachiever; benefit orientation; game theory; behavior choice

In today's world, economic competition is actually the competition of science and technology and national quality competition. Since the 1980 s, education institution changed the model that only pays attention to high level students, begun to pay close attention to development of every student, especially to school underachievers. Two kinds of reason can explain the formation of vocational school underachiever, one is objective reason and the other is subjective reason. Objective reasons conclude low enrollment of vocational schools that makes some low quality students enter into school, and negative influences of external environment. Subjective reasons include limitation of students' bounded rationality and decision-making ability that make students' behaviors do not conform to social norms ${ }_{[1]}$. In this paper the author tries to use game theory analysis method, discuss the mechanism of underachiever behavior choosing, and then put forward feasible management countermeasures.

\section{PHENOMENON OF VOCATIONAL SCHOOL UNDERACHIEVER AND REASONS}

Psychologist think underachiever problem as physiological and psychological phenomenon. They think the reasons of underachiever formation include not only intelligent hysteresis, but also internal factors such as physical factors, psychological factors, and external factors that cause mental and physical changes. WuChuan Xiong, professor of East China Normal University, took education of underachiever as a subject to study, established the pattern of "understanding education", and got remarkable achievements in experiment. "Understanding education" provides us with a new education pattern focusing on underachievers, focusing on development of students' nonintellectual factors, paying attention to the progress of all students, paying attention to quality education ${ }_{[2]}$.

The threshold of the vocational school recruitment has been lowered, so that student number of vocational schools has increased, and student quality has dropped. After these students study in vocational schools, their grades fall behind, self-discipline and self-control ability are poor, and they don't want to accept the instruction and constraint of school management. Students' own reasons and bad impacts of external factors result in vocational schools underachiever. This is surface reason.

Underachiever's subjective factors include:

- Because vocational school students' age range is from 14 to18 years old, their physical and mental development is in transformation period, easy to produce behavioral deviation.

- They are lack of in-depth consideration for series of problems, such as future career path.

- Lack of active enterprising spirit, regarding learning as a burden.

- $\quad$ Lack of self-discipline ability, when facing setbacks and difficulties, often due failure to external factors.

Objective factors include:

- Parents of students are busy working and only emphasis on material life, lack of guidance to children's education and children's moral standards.

- Some education workers make wrong evaluation in the teaching process because of the cognitive deviation, and then only keep watchful eyes on high level students, take underachiever as baggage. These actions hurt underachieves' self-esteem, and produce rebellious psychology.

To sum up, the formation of underachiever is result of interaction between internal and external factors. There are 
objective factors and subjective factors. Students are rational behavior individuals. In given external environment, based on their own characteristics and understanding of external environment. They will pursue maximization of their own interests, and make behavior choices that they think the optimal performance. To solve underachiever's management problems, attention should be paid to two sides which are external environment and students' own factors, in view of student's behavior orientation.

\section{GAME THEORY ANALYSIS ON VOCATIONAL SCHOOL UNDERACHIEVER BEHAVIOR}

Economics principle tells us that economic individual is always to pursue self-interest maximization and to choose specific behavior in a certain constraint conditions ${ }_{[3]}$. Behavior refers to activity that somebody makes with capacity of conscious action.

The earning of underachiever behavior is obtaining relatively free way of life, yet the loss is the reputation loss and bad impact of future employment. When students choose behavior they will consider from two aspects. One is the comparison between profit and loss, if income is lower than loss, they will choose good behavior, and otherwise, they will choose bad behavior. Second is the possibility of estimated behavior results occurring, if the possibility of abnormal behavior leading to adverse consequences is large, behavior probability is small, or with large probability ${ }_{[4]}$. For early expression, we called the two types of student's behavior as working hard and not working hard.

As the other side of the game, social constraint forces also have gains and losses. Earnings of improving students' quality are self-evident, but some costs have to be paid: to create a good environment, parents and teachers should pay more time and opportunity costs (such as, parents can use the resources on economic activities; teachers can use the resources on outstanding students). Society, parents and teachers are also under the principle of their own benefit maximization, to choose guidance and supervision of students or not, and in accordance with a certain probability distribution of behavior choice: one is to compare profit with loss; the other is to estimate possibility. For expression of convenience, we simplify environmental factors to two kinds: strict system and tolerate system.

\section{A. Basic hypothesis}

Basic assumptions are as follows:

- Students are rational, in order to maximize their own interests.

- Game rule is established, open, transparent, and behavior choice of students is a complete information static game.

- Students working hard don't necessarily make a good performance, because existence of competition between classmates, probability of success is $P$.

- Students who are considered as underachiever have reputation losses and economic losses, including not obtaining scholarship, and not be recognized by society after graduation.

\section{B. Construction of Payoff matrix}

Payoff matrix reflects benefit and cost of game both parties got when taking different strategy in game process and it is base of behavior choice. Parameter hypothesis is as following from two aspects of benefit and cost.

The cost of students studying hard is $L$, including focusing attention in class, preparing for exam, taking part in collective activities, paying extra labor in order to improve their own quality, etc. The earnings of efforts to become excellent students is $U$, including winning a scholarship and better job opportunities; the earnings of not studying hard to become underachiever but obtaining more freedom are $F$, at the same time, there are reputation losses $R$, as well as the harmful effect $H$ to future career opportunity after graduation.

The cost of strict social system needed is C, including: establishing objective precise talent evaluation program (if underachiever can find a good job, the social system will not motivate students to be a top student with more additional works) the guide of social thought, more time and energy parents spending on students, more time and energy teachers spending to help low level students, etc. Society will get profit of $A$ from excellent students and anticipated contribution to society from qualified students.

TABLE I. GAME PAYOFF MATRIX OF SOCIAL CONSTRAINT FORCE AND UNDERACHIEVER BEHAVIORTABLE TYPE STYLES

\begin{tabular}{|l|l|l|l|c|}
\hline \multirow{2}{*}{$\begin{array}{c}\text { Social } \\
\text { force }\end{array}$} & \multicolumn{4}{|c|}{ Underachiever } \\
\cline { 2 - 5 } & \multicolumn{3}{|c|}{ Work hard } & \multicolumn{2}{c|}{ Not work hard } \\
\hline $\begin{array}{l}\text { Strict } \\
\text { system }\end{array}$ & $A-C$ & $P U-L$ & $-C$ & $-R-H$ \\
\hline $\begin{array}{l}\text { Tolerate } \\
\text { system }\end{array}$ & 0 & 0 & 0 & $F$ \\
\hline
\end{tabular}

\section{Determination on Nash equilibrium of mixed strategy}

Both Social constraint force and underachiever inevitably seek the Nash equilibrium of mixed strategy under the principle of benefit maximization.

1) Determination on optimal probability of students' working hard behavior choice: Given the probability of students working hard choice is $\beta$, expected profit functions of social constraint forces to choose strict system or tolerance system are as following respectively:

$\operatorname{Er}(\beta, 1)=(A-C) \beta+(-C)(1-\beta)=A \beta-C \beta-C+C \beta=A \beta-C$

$\operatorname{Er}(0, \beta)=0 \beta+0(1-\beta)=0$

From $\operatorname{Er}(\beta, 1)=\operatorname{Er}(0, \beta)$, we can conclude the optimal probability of students' working hard behavior choice:

$$
\beta *=C \mid A
$$

2) Determination on optimal probability of social constraint forces' strict system: Given the optimal probability of social constraint forces' strict system choice is $\alpha$, the expected profit functions of students' working hard choice and not working hard choice are as following:

$E s(\alpha, 1)=(P U-L) \alpha+(-R-H)(1-\alpha)=(P U-L) \alpha$

$E s(0, \alpha)=(-R-H)(-\alpha)+F(1-\alpha)=(-R-H-F) \alpha+F$ 
From $E s(\alpha, 1)$ Es $(0, \alpha)$, we can conclude that the optimal probability of social constraint forces' strict system choice:

$$
\alpha^{*}=F \mid(P U+F+R+H-L)
$$

3) Nash equilibrium of mixed strategy: $\left(\alpha^{*}, \beta^{*}\right)$ is the mixed strategy Nash equilibrium of social constraint forces and student behavior choice, corresponding to the optimal behavior choices of both parties. At this point only one party's changing strategy does not increase its own earns. Namely, under the condition of one party's invariable action, the other side is rational and is not initiative to break the balance.

\section{Effective way to improve underachiever education}

The effective ways to improve underachiever education are as following: enlarge the space of students' working hard choice, and reduce the space of social constraint forces' strict system choice.

1) Space of students' working hard choice and influencing factors

To make benefits greater than expected profit, students will take corresponding action based on severe degree of social constraint forces. When the probability of social constraint forces' strict system is less than $\alpha^{*}$, not working hard is the best choice for students. When the probability of social constraint forces' strict system is more than $\alpha^{*}$, working hard is the best choice for students. Name $V S=\{\alpha \mid \alpha$ $\in\left(\alpha^{*}, 1\right)$ 'the space of students' working hard choice.

From the partial derivative of (2), $\alpha^{*}$ is increasing function of $F$ and $L, \alpha^{*}$ is decreasing function of $P, U, R$ and $H$. To expand the space of students' working hard choice, it is necessary to reduce $\alpha^{*}$, namely lower $F$ and $L$, increase $P, U$, $R$, and $H$.

2) Space of social constraint forces' strict system choice and influencing factors

Also, in order to make actual income greater than equilibrium expected profit, social constraint forces will choose corresponding action according to effort degree of students. When the probability of students' working hard is less than $\beta^{*}$, the best choice of social constraint forces is strict system. When the probability of students' working hard is more than $\beta^{*}$, the best choice of social constraint forces is tolerant system. Name $V T=\left\{\beta \mid \beta \in\left(0, \beta^{*}\right)\right\}$ the space of social constraint forces' strict system choice.

From the partial derivative of (1), $\beta^{*}$ is increasing function of $C, \alpha^{*}$ is decreasing function of $A$. To narrow the space of social constraint forces' strict system choice, it is necessary to reduce $\beta^{*}$, namely lower $C$, increase $A$.

\section{MANAGEMENT MEASURES TO SOLVE PROBLEMS OF UNDERACHIEVER}

Based on the above analysis on influencing factors of the space of social constraint forces' strict system choice and the space of students' working hard choice, we can put forward some countermeasures to improve underachiever education level, from two aspects: school education management mode and school factors.

\section{A. Change education management mode}

Change education management mode from the following aspects: reducing the freedom $F$ students got from not working hard, reducing the labor $L$ students paid to improve their quality, increasing students' successful probability $P$ after efforts, increasing the material rewards $U$ students gained from excellent performance.

- Construct students' comprehensive evaluation system. The traditional performance evaluation system emphasizes on students' grade, which gives underachievers too big pressure, increases cost of their studying hard, and reduces realization possibility to get rid of the underachiever position. Evaluation system should change single evaluation method, set up parallelways evaluation mechanism, which can develop underachievers' specialty, help underachievers build confidence, and provide them with more development $\operatorname{room}_{[5]}$.

Change appraisal mode for teacher. Under previous appraisal mode, achievements of students are key points to teachers' performance, so teachers put time and energy on outstanding students, and pay less attention to underachievers. The new appraisal mode should make teachers see every student as equal individual, no mater he or she is high level student or underachiever, to create a relaxed growth environment for so called underachievers.

- $\quad$ Enrich students' spare life. In underachievers' eyes, leisure life include: playing games in net cafe, wandering out school, listening music or reading novels in class and so on. It is reasonable to infer that, these behaviors we think bad are student's rational demands in some degree. If school can organize rich and colorful after-class activities, the motivation of students' bad behavior will be reduced.

\section{B. Strengthen social force guide to student behavior}

To improve constraints and incentives that social power presses on students, the following actions are necessary: lower the cost of $C$ that social set up strict restriction system, increase employment possibility $H$ for excellent students after graduation, and increase expected contribute $A$ that excellent students could bring to the society

- $\quad$ Lead positive progress of mainstream social value. It is necessary to develop positive values and happy and healthy life style in the whole society, to stimulate students' desire to success, to enhance sense of social responsibility.

Establish just and fair society employment system. If high level students can not get a good job opportunity, but some low level students can get one because of their good family background, efforts to study hard will be lowered down for every one ${ }_{[6]}$.

Help students set up right career planning. Good job opportunities are in smaller proportion in the whole society, so not every body can become social elites. If most people, who can't become elite, can find right job 
opportunity and can get good happy life after graduation, they will have more learning motivation during school ${ }_{[7]}$.

\section{CONCLUSIONS}

The problem of underachiever education is one of great afflictions for society and schools. Underachiever's existence is an objective fact, so we must face up to this phenomenon. Underachiever's formation is result of students' behavior choice, and students' behavior choices are rational based on institutional constraints to maximize their own interests. The underachiever's management should guide students to take the appropriate action based on students' rational demand, social system and education system. At the same time, because underachiever education problem is a systematic project, it is difficult to obtain expected result only relying on one aspect, long time close cooperation of various social forces is needed. More attention should be paid to this point.

\section{REFERENCES}

[1] Jiangzhe Zhang, "The cause of formation of vocational schools underachiever and education countermeasures" J. Journal of Jiangxi normal university of science and technology, June 2002,pp.26-28.

[2] Xueni Zhang, "Higher vocational colleges underchiever characteristics cause analysis and counterneasures" J. Ningbo college engineering journal, vol. 1, pp. 118-120, January 2005.

[3] Weiying Zhang, Game Theory and Information Economics, 3rd ed., Shanghai SDX joint publishing company, Shanghai people's publishing house, 2002,pp.35-45.

[4] Shimin Sun, "Game analysis and countermeasures of college students' exam cheating behavior" J. High agricultural education, August 2004,pp.26-29.

[5] Xin Zhao, "concerning the underachiever education orientation changes" J. Modern education review, September 2009,pp.39-42.

[6] Shan Huang, "countermeasures analysis on political theory course teaching of underachiever" J. China power education, vol. 16, pp.166168, 2010.

[7] Hui Yan, "The humanistic thinking of underchiever transformation" J. Education and career, March 2011,pp.189-191. 